ORIGINAL ARTICLE

\title{
Genomic instability in radial growth phase melanoma cell lines after ultraviolet irradiation
}

\author{
M R Hussein, A K Haemel, O Sudilovsky, G S Wood
}

J Clin Pathol 2005;58:389-396. doi: 10.1136/icp.2004.021519

See end of article for authors' affiliations

Correspondence to: $\operatorname{Dr} M$ R Hussein, Department of Pathology, Assiut University Hospitals, Assiut, Egypt; mrh17@ swissinfo.org

Accepted for publication 14 September 2004

\begin{abstract}
Background/Aims: Although ultraviolet (UV) irradiation, apoptosis, and genomic instability are all potentially involved in the pathogenesis of melanoma, in vitro studies investigating these changes in the radial growth phase of this neoplasm are still lacking; therefore, this study was designed to investigate these changes.

Method: An in vitro system consisting of three radial growth phase Wistar melanoma cell lines (WM35, WM321 1, and WM1650) was established. Cells were UV irradiated $\left(10 \mathrm{~mJ} / \mathrm{cm}^{2}\right.$ for UVB and $6 \mathrm{~J} / \mathrm{cm}^{2}$ for UVA), harvested after UV exposure, and evaluated for viability and apoptosis using Trypan blue and terminal deoxynucleotidyl transferase mediated dUTP digoxigenin nick end labelling assays, respectively. Polymerase chain reaction based microsatellite assays were used to examine the cell lines for the presence of microsatellite instability (MSI) using 21 markers at the 1p, 2p, 3p, 4q, 9p, and 17p regions.

Results: Exposure to UV initiated progressive cell death associated with pronounced apoptosis, with UVA having a greater effect than UVB. MSI was found in UVB (WM35 and WM3211) and UVA (WM35) irradiated cell lines at 1p,9p, and 17p, but not in non-irradiated cells. The prevalence of MSI was higher after UVB irradiation (14\%) than UVA irradiation (4.7\%), and was most frequently found at DIS233.

Conclusions: The ability of erythemogenic UV irradiation to induce both apoptosis and MSI in radial growth phase melanoma cells is suggestive of its role in melanoma pathogenesis. This instability may reflect a hypermutability state, oxidative stress induced DNA damage, replication infidelity, or a combination of these factors.
\end{abstract}

\begin{abstract}
"Several in vivo studies have revealed the involvement of ultraviolet irradiation, apoptosis, and microsatellite instability in the advanced stages of cutaneous malignant melanoma"

Microsatellites are repetitive DNA sequences of $1-6$ base pairs scattered primarily in the non-coding regions of DNA. Neither the factors that restrict them to these regions nor their exact biological roles are clear. ${ }^{8}$ Microsatellite instability (MSI) is a variation in microsatellite pattern length between tumorous and matching non-tumorous tissues. ${ }^{8}$ MSI can be separated into high (MSI-H; $>30 \%$ of tested markers), and low (MSI-L; $<30 \%$ of tested markers) instability patterns. MSI-H has been described in families with hereditary nonpolyposis colorectal cancer and is associated with mutations in mismatch repair genes. Although MSI-L has also been reported in several tumours, ${ }^{8}$ including benign naevi, melanocytic dysplastic naevi, ${ }^{8}$ primary $\mathrm{CMM}^{89}$ and metastatic $\mathrm{CMM}^{8}{ }^{8}$ the underlying mechanisms of this instability pattern are still unknown.
\end{abstract}

Several in vivo studies have revealed the involvement of $\mathrm{UVR}^{10-12}$ apoptosis, and $\mathrm{MSI}^{89}$ in the advanced stages of CMM. In these tumours, several molecular pathways mediate the activation of a variety of prosurvival and proapoptotic proteins that seem to play a role in melanoma tumorigenesis. ${ }^{13}$ However, in vitro studies examining these changes in the early stages of CMM are scarce. Therefore, we used an in vitro system consisting of control (non-irradiated) and irradiated Wistar melanoma (WM) cell lines (non-tumorigenic, radial growth phase cells) to explore cell viability, apoptosis, and genomic instability after UVR. We divided the cell lines into three groups: UVA irradiated, UVB irradiated, and non-irradiated (control) groups. We carried out three sets of experiments to investigate the following questions: (1) what is the effect of a single exposure to UVA or UVB on cell viability? (2) What is the effect of a single exposure to UVA or UVB on apoptosis? (3) What are the genetic alterations in microsatellites associated with a single UVR dose in radial growth phase melanomas?

\section{MATERIALS AND METHODS \\ Cell culture}

Three human WM cell lines (a generous gift from Dr M Herlyn, Wistar Institute, Philadelphia, USA), derived from (non-tumorigenic) radial growth phase CMMs, were established as described by Dr Herlyn (fig 1). Two cell lines (WM35 and WM3211) were maintained in DMEM medium supplemented with $10 \%$ fetal calf serum and insulin ( $5 \mathrm{mg} / \mathrm{ml}$ ), and the third one, WMl650, was maintained in

\footnotetext{
Abbreviations: $C M M$, cutaneous malignant melanoma; $\mathrm{LOH}$, loss of heterozygosity; MED, minimal erythema dose; MSI, microsatellite instability; MSI-H/L, high/low microsatellite instability; PCR, polymerase chain reaction; TUNEL, terminal deoxynucleotidyl transferase mediated dUTP digoxigenin nick end labelling; UVA/B, ultraviolet A/B; UVR, ultraviolet irradiation; WM, Wistar melanoma
} 

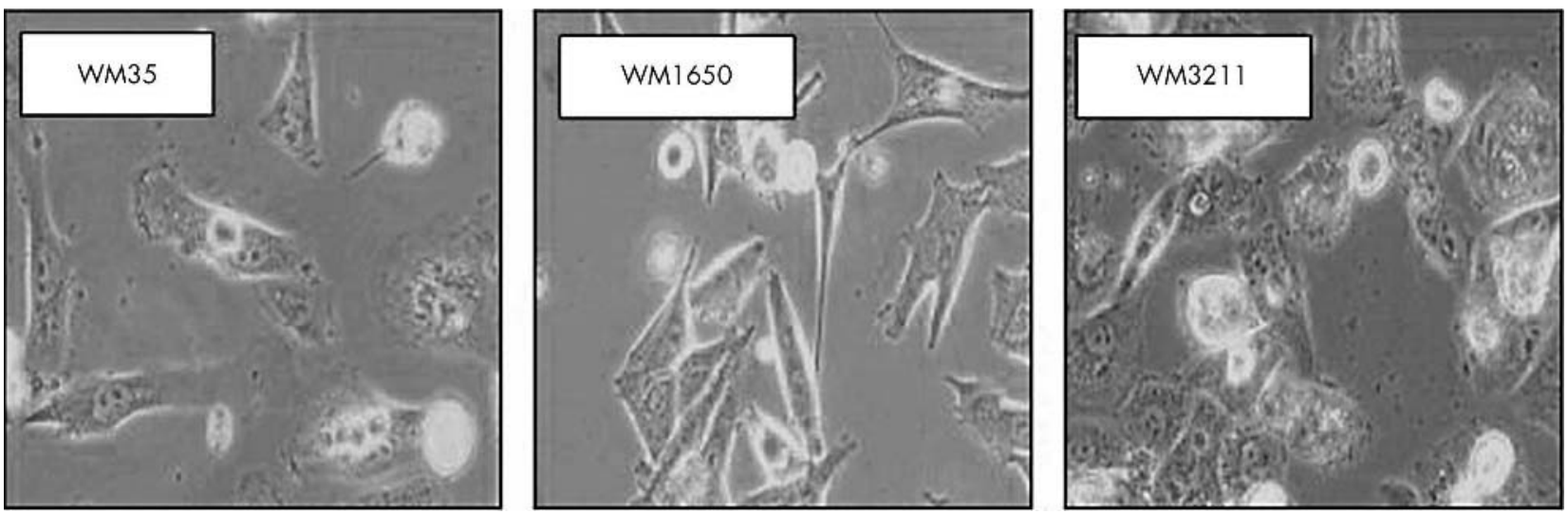

Figure 1 Three human Wistar melanoma cell lines, derived from (non-tumorigenic) radial growth phase melanomas, were established as described by the supplier. Two cell lines (WM35 and WM3211) were maintained in DMEM medium supplemented with 10\% fetal calf serum and insulin (5 mg/ $\mathrm{ml}$ ), and the third one, WM1650, was maintained in RPMI medium supplemented with 10\% fetal calf serum and $10 \mathrm{ng} / \mathrm{ml}$ TPA (12-Otetradecanoylphorbol 13-acetate).

RPMI medium supplemented with $10 \%$ fetal calf serum and $10 \mathrm{ng} / \mathrm{ml}$ TPA (12-O-tetradecanoylphorbol 13-acetate).

\section{The rationale for selecting specific UVR dosages}

A dose of $10 \mathrm{~mJ} / \mathrm{cm}^{2}$ UVB was used according to the following rationale: (1) in vivo, doses of UVB in the range of 30 to $150 \mathrm{~mJ} / \mathrm{cm}^{2}$ ( 1-5 minimal erythema doses; MED) are normally encountered and (2) erythema induced by solar UVB results from the penetration into the dermis of approximately $10 \%$ of the total UVB dosage. Therefore, in vitro UVB doses ranging from 3 to $15 \mathrm{~mJ} / \mathrm{cm}^{2}$ (or l-5 MED dermal equivalents) are equivalent to the amount of irradiation reaching melanocytes at the basal layer that is needed to cause sunburn $(\sim 1 \mathrm{MED}) .{ }^{14}{ }^{15}$ In contrast, for UVA, the transmission through the epidermis is $\sim 19 \%$ (at wavelength $365 \mathrm{~nm}$ ), and its MED is $15-20 \mathrm{~J} / \mathrm{cm}^{2}$. The $6 \mathrm{~J} / \mathrm{cm}^{2}$ dosage used for UVA is the minimum dose that can induce oxidative stress and compromise the antioxidant enzyme system. Of note, these last two effects are responsible for the potential carcinogenic capability of UVA..$^{16-18}$

\section{UV irradiation}

The cells were maintained in tissue culture flasks $\left(25 \mathrm{~cm}^{2}\right)$ until they attained confluence. The cells were then trypsinised, suspended in medium, and seeded into several $100 \mathrm{~mm}^{2}$ petri dishes $\left(1 \times 10^{5}\right.$ cells $\left./ \mathrm{ml}\right)$ in phosphate buffer saline. For UVB irradiation, the cells were irradiated under a bank of six FS-40 UVB lamps (Philips, Bloomfield, New Jersey, USA) from which UVB and UVC wavelengths, not normally present in natural solar radiation, were filtered out using Kodacel cellulose film (Eastman-Kodak, Rochester, New York, USA). The light contained radiation in the wavelength of the UVB range $(290-320 \mathrm{~nm})$. The total dose of irradiation ( $10 \mathrm{~mJ} / \mathrm{cm}^{2}$ for UVB) was calculated using a radiometer (IL-700) with UVB detectors (SED240; International Light Inc, Newburyport, Massachusetts, USA). For UVA irradiation, the cells were irradiated under a bank of two Q-Panel UVA (UVA-340 lamp, ASTMG-53) fluorescent lamps (Q-Panel, Cleveland, Ohio, USA). Most of the radiation from this lamp is in the UVA region (320-400 nm), with a small amount in the UVB spectrum. The total dose of irradiation $\left(6 \mathrm{~J} / \mathrm{cm}^{2}\right.$ for UVA) was calculated using a radiometer (IL-700) with UVA detectors (SED033; International Light Inc). Immediately after irradiation, the phosphate buffered saline was removed, and the cells were overlaid with fresh medium and returned to the incubator. Controls (non-irradiated cells) were handled similarly, but were not exposed to UV irradiation. The cells were evaluated for viability, apoptosis, and the presence of genetic changes (including MSI and loss of heterozygosity $(\mathrm{LOH})$ ) after UV irradiation.

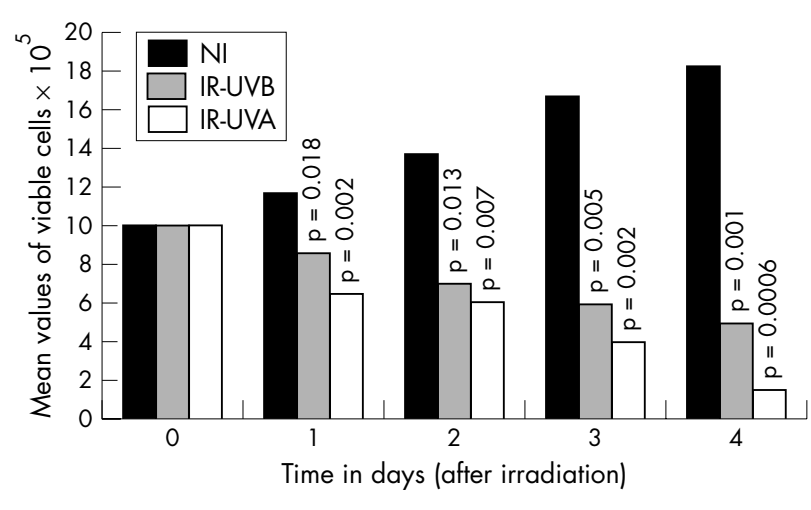

Figure 2 Summary of viability assays in ultraviolet (UV) irradiated WM35 cell lines using Trypan blue dye exclusion test. IR-UVA, UVA irradiated cells; IR-UVB, UVB irradiated cells; NI, non-irradiated.

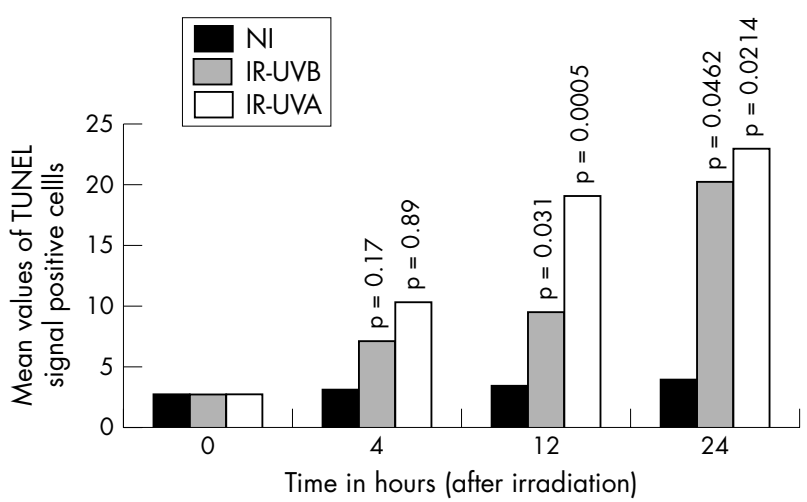

Figure 3 Semiquantitative analysis of TUNEL (terminal deoxynucleotidyl transferase mediated dUTP digoxigenin nick end labelling) positive WM35 cells after ultraviolet (UV) irradiation. IR-UVA, UVA irradiated cells; IR-UVB, UVB irradiated cells; NI, non-irradiated. 


\section{Cell viability}

Plasma membrane function and structural integrity were determined by the Trypan blue exclusion test. ${ }^{19}$ Briefly, cell suspensions at a high concentration $\left(10^{6}\right.$ cells $\left./ \mathrm{ml}\right)$ were prepared by trypsinisation, centrifugation, and resuspension. Equal amounts $(0.1 \mathrm{ml})$ of cell suspension and the Trypan blue dye were mixed thoroughly, transferred to the edge of a cover slip, allowed to run into the counting chamber of a haemocytometer, and left for one to two minutes. Both the number of stained cells and the total number of cells were then counted. The percentage of viable cells was determined by calculating the percentage of unstained cells.

\section{Detection of apoptotic cells}

To evaluate the apoptotic response after the UV exposure described above, the irradiated and non-irradiated WM cell lines were harvested at $0,4,12$, and 24 hours after irradiation. We examined apoptosis with the terminal deoxynucleotidyl transferase mediated dUTP digoxigenin nick end labelling (TUNEL) assay before and after irradiation. The TUNEL technique was performed using the commercially available QIA33TDT-FragEL ${ }^{\mathrm{TM}}$ kit (Oncogen Research Products, Boston, Massachusetts,USA) in accordance with the manufacturer's directions. Positive controls were obtained from the manufacturer and consisted of HL-60 promyelocytic leukaemia cells. Some specimens from UV exposed WM cell lines were used as negative controls by substituting distilled water for terminal deoxynucleotidyl transferase in the protocol, as suggested by others. ${ }^{20}$ The sections were then examined with a $\mathrm{BH}-2$ Olympus microscope. The cells were then processed for evaluation by transmission electron microscopy (Tecani 10 EM and Gatan MSC with digital micrograph camera).

\section{Selection of microsatellite markers}

A panel of 21 microsatellite markers ( 12 markers at $1 p$, five at $9 p$, and one each at $2 p, 3 p, 4 q$, and $17 p$ ) was obtained from Research Genetics (Huntsville, Alabama, USA), and their characteristics are available online (http://www.resgen.com/ products/HuMPs.php3).

\section{DNA extraction}

DNA was extracted from the cell lines using the DNeasy ${ }^{\mathrm{TM}}$ tissue kit (Qiagen, Valencia, California, USA), as described by the manufacturer.

\section{PCR based microsatellite assay}

The polymerase chain reaction (PCR) was performed in a $10 \mu \mathrm{l}$ volume containing $\mathrm{l} \times$ PCR buffer $(10 \mathrm{mM}$ Tris, $50 \mathrm{mM}$ $\mathrm{KCl}(\mathrm{pH} 8.3$ ), and $0.02 \%$ Tween 20), $0.2 \mu \mathrm{M}$ each of the
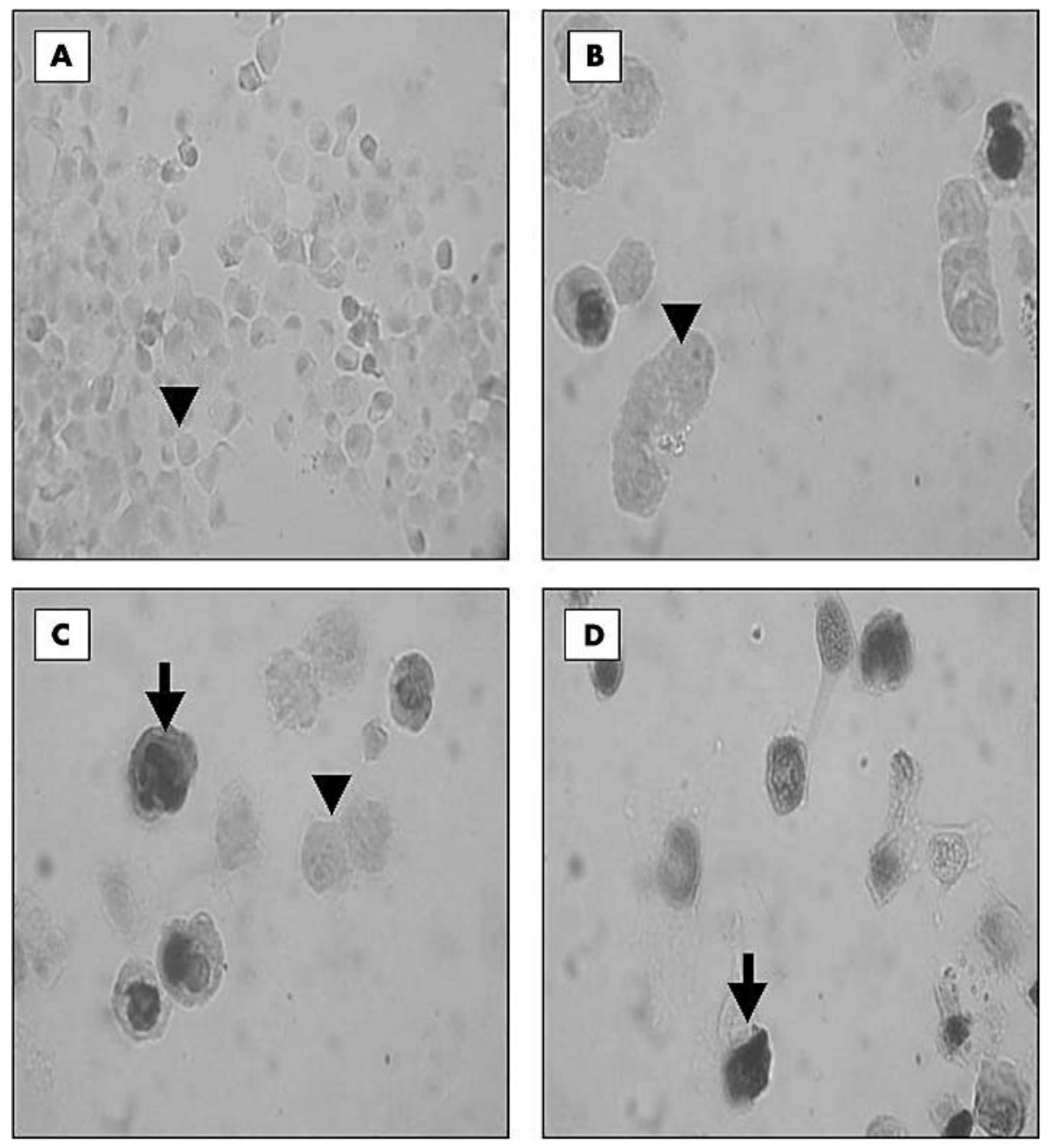

Figure 4 Apoptosis in Wistar melanoma cell lines. (A) Negative control; (B-D) apoptosis in cell lines at four, 12, and 24 hours after ultraviolet (UV) irradiation, respectively. TUNEL (terminal deoxynucleotidyl transferase mediated dUTP digoxigenin nick end labelling) signal positive (arrowhead) and negative (arrow) cells. Although both UVA and UVB induced apoptosis in the Wistar melanoma cell lines at the designated time intervals, UVA irradiation induced more apoptotic cell death than UVB irradiation. 

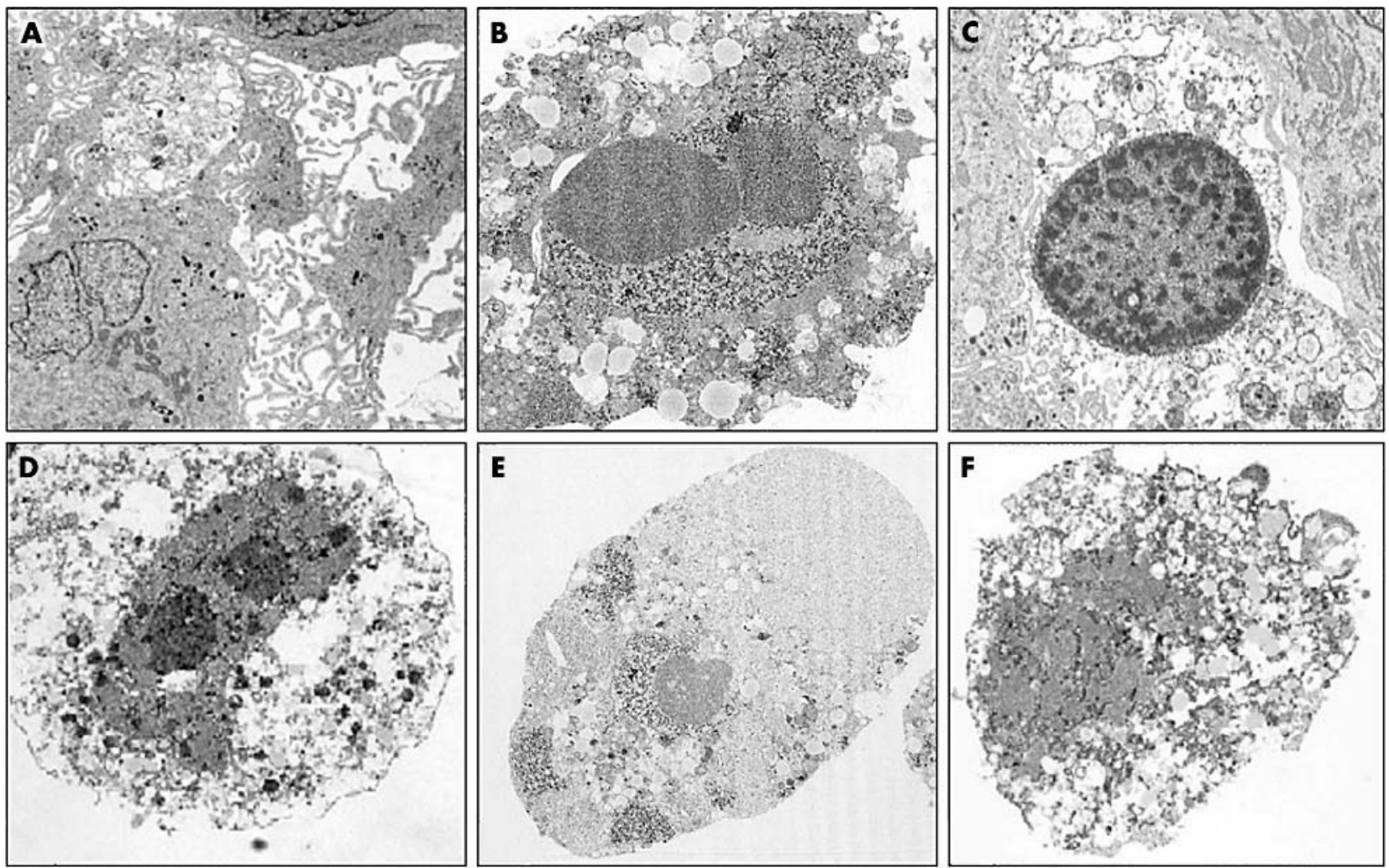

Figure 5 (A) Ultrastructural features of non-irradiated melanoma cell lines (original magnification, $\times 6700$ ). Ultrastructural features of apoptosis in the irradiated Wistar melanoma cell lines included: (1) incomplete condensation of the chromatin pattern displaying a microgranular network (B; original magnification, $\times 4700$ ); (2) condensed chromatin near the periphery, close to the nuclear envelope seen as one or several large homogenous masses $(C$ and $D$; original magnification, $\times 9400$ and $\times 49000$, respectively); (3) irregularity of the nuclear membrane (D; and $E$, F; original magnification, $\times 6700)$; and (4) partially disrupted chromatin as indicated by the presence of one or more nuclear vacuoles (C, E, and F).

unlabelled and ATP $\left[\gamma^{33} \mathrm{P}\right]$ (ICN Biomedical, California, USA) labelled primers, $1 \mu \mathrm{l}$ of DNA supernatant, $0.2 \mathrm{U}$ of Taq DNA polymerase (PGC Scientific, Frederick, Maryland, USA), $125 \mathrm{mM}$ each of dNTPs, and $1.5 \mathrm{mM} \mathrm{MgCl}_{2}$. PCR was performed using a "touch down" approach: five minutes at $94^{\circ} \mathrm{C}$, followed by 36 to 38 cycles of one minute at $94^{\circ} \mathrm{C}$, one minute at $56-60^{\circ} \mathrm{C}$, and one minute at $72^{\circ} \mathrm{C}$; with a final elongation step for nine minutes at $72^{\circ} \mathrm{C}$. A "hot start" was also used by adding Taq DNA polymerase when the temperature in the initial ramp was $>80^{\circ} \mathrm{C}$. PCR products were resolved on a $6 \%$ Long Ranger sequencing gel (FMC, Rockland, Maine, USA) and exposed to BioMax MR film (Kodak) for 24-72 hours. All PCR reactions and gel loadings were repeated at least twice, and only identical results were reported.

\section{Assessment of MSI}

MSI was defined by variations in the DNA banding pattern between irradiated and non-irradiated cell lines. Because we were working on cell lines without matching normal control DNA, only irradiated cell lines presenting with more than two alleles for each locus were considered unstable. ${ }^{21}$ Irradiated cell lines with MSI at one or more loci were scored as MSI positive. $^{8}$ Instability at more than $30 \%$ of the tested loci was used as a cut off between MSI-L and MSI-H. Samples without MSI were scored as microsatellite stable (MSS). During this assay, irradiated cell lines were simultaneously assessed for LOH. The heterozygosity loss was evaluated by comparing the intensities of the two alleles in informative cases. $\mathrm{LOH}$ was scored whenever the radiographic signal of one allele was absent or $50 \%$ reduced in the tumours, as determined by visual comparison of the allele intensities and use of the SciScan 5000 densitometer.

\section{RESULTS}

\section{Effects of UV light on cell viability}

The UV treated cells showed rounding up and detachment from the culture plate when compared with the control cells. Comparison of the mean values of viability among irradiated and non-irradiated cell lines revealed two facts: (1) both UVA and UVB induced pronounced cell killing within 24 hours after irradiation; and (2) UVA induced more cell killing than UVB. Similar responses were seen in all three cell lines, and fig 2 provides a summary of the viability assays in WM35. This figure shows that the mean viability was highest in nonirradiated cells, followed by the UVB irradiated cells, with the lowest values being seen in the UVA irradiated cells. The mean viability values of the non-irradiated and irradiated cell lines were significantly different, and the $p$ values were lower for the UVA irradiated group, indicating greater significance (fig 2).

\section{DNA fragmentation assay (TUNEL)}

None of the negative controls stained with the TUNEL technique showed immunoreactivity, whereas positive TUNEL staining was seen in the positive controls. Semiquantitative evaluation of apoptosis by counting the number of TUNEL signal positive cells in both the nonirradiated and UV irradiated cell lines revealed the following two facts: (1) in the control (non-irradiated) cells, few cells showed positive signals at the designated times, whereas UV treated cells showed greatly increased numbers of positively 
A

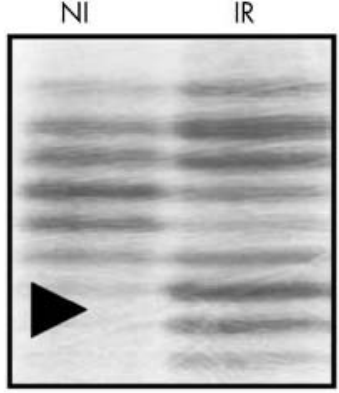

D1S2734

B

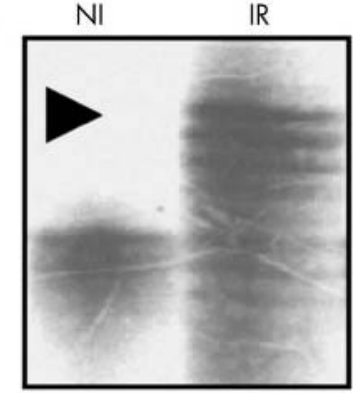

D1S2663

C

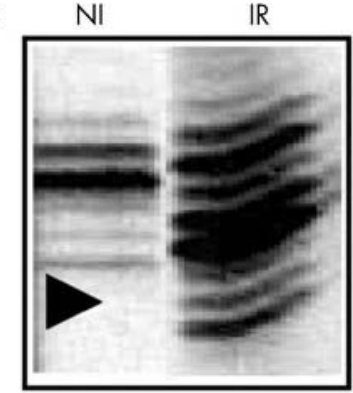

D1S233

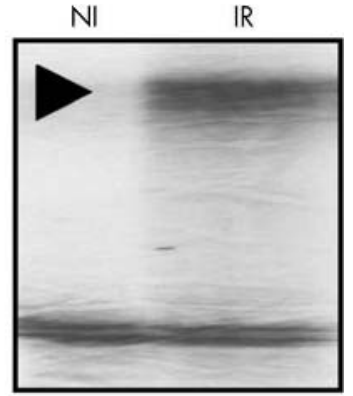

IFNA

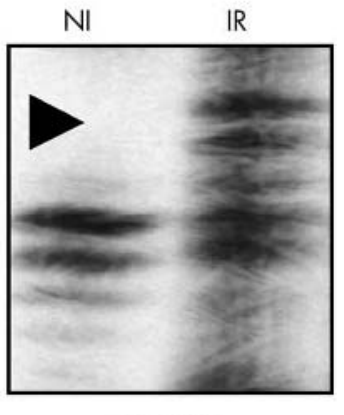

D1S233

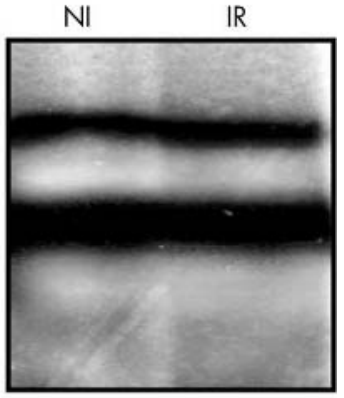

MYCL1

Figure 6 Microsatellite instability (MSI) in Wistar melanoma cell lines. MSI after ultraviolet (UV) B irradiation in (A) WM3211 and (B) WM35 cell lines. (C) MSI (D1S233) and microsatellite stability (MYCL1) after UVA irradiation in WM35. Instability was charactarised by the appearance of novel bands in the irradiated cell lines (arrowheads). IR, irradiated cells; NI, non-irradiated cells.

stained cells; and (2) UVA irradiation induced more apoptosis than UVB. A similar response was seen in all three cell lines, and figs 3 and 4 provide a summary of the TUNEL assay results in WM35 cells. These figures reveal that the apoptotic mean values were the highest in the UVA irradiated cells, followed by the UVB irradiated cells, with the nonirradiated cells showing the lowest values. The mean apoptotic values were significantly different between the non-irradiated and irradiated cell lines, with the $\mathrm{p}$ values being lower in the UVA irradiated group, indicating greater significance (fig 3). Positive TUNEL results are indicative, but not proof of, the presence of apoptotic cells, because there are several forms of programmed cell death that can induce DNA degradation in the absence of apoptotic caspase activation. Therefore, the apoptotic activity in our series was also confirmed by the ultrastructural detection of characteristic apoptotic patterns in the irradiated WM cell lines. These features included: (1) incomplete condensation of the chromatin pattern, displaying a microgranular network

(fig 5B); (2) condensed chromatin near the periphery, close to the nuclear envelope, seen as one or several large homogenous masses (fig 5C, D); (3) irregularity of the nuclear membrane (fig 5D-F); and (4) partially disrupted chromatin, as indicated by the presence of one or more nuclear vacuoles (fig 5C, E, F).

\section{Frequency of MSI after UVR}

MSI was detected in the WM35 and WM3211 cell lines after UVR, but not in WM1650, in duplicate sets of experiments. The allelic pattern in irradiated cells was characterised by the presence of novel bands above or below those present in nonirradiated cells (fig 6). MSI was found at four loci in the WM35 cells (D1S2734, D1S233, MYCL1, and IFNA) after UVB irradiation and at one locus (D1S233) after UVA irradiation. In the WM3211 cells, MSI was seen after UVB irradiation only, and was found at five loci (DIS2663, D1S233, D1S513, D9S171, and TP53). Overall, the most frequently affected locus was DIS233. In keeping with the MSI-L pattern reported previously by us in excised melanocytic dysplastic naevi and CMM, ${ }^{8}$ the frequency of MSI ranged from $0.0 \%$ to $19.0 \%$ and from $0.0 \%$ to $4.7 \%$ after UVB and UVA irradiation, respectively (table 1 ).

\section{DISCUSSION}

Previous studies of excised melanocytic skin tumours revealed the involvement of UVR, apoptosis, and a gradual increase in MSI, which correlated with the progression and increased aggressiveness of these tumours..$^{22-24}$ Based on these studies, we hypothesised that UVR contributes to the molecular pathogenesis of CMM arising on sun-exposed skin by causing MSI, which results in mutations in genes involved in neoplastic transformation and tumour progression. To test our hypothesis, we exposed radial growth phase CMM cell lines to UVA and UVB and examined them for viability, the presence of apoptosis, and MSI using TUNEL and PCR based microsatellite assays.

In agreement with other studies, our data revealed that UVR (in the range capable of causing sunburn in vivo) generally induces cell death and a drastic increase in the apoptotic activity in the irradiated WM cell lines, ${ }^{25-28}$ suggesting excessive underlying DNA damage beyond the capacity of the repair system. ${ }^{29}$ This DNA damage may be either in the form of accumulated pyrimidine dimers (induced by UVB) or oxidatively modified bases (induced by UVA). The accumulation of these products as a possible mechanism for the apoptosis seen in WM cell lines concurs with the apoptotic changes induced by UVA and UVB. ${ }^{28} 30$ Because DNA absorbs little, if any, UVA, the genotoxicity of UVA is mostly the result of the generation of reactive oxygen radicals, ${ }^{6}$ which have a definitive role in apoptosis. ${ }^{31}$ In support of this principle, exposure to $\mathrm{H}_{2} \mathrm{O}_{2}$ is a potent inducer of apoptosis in HL- 60 cells, ${ }^{32}$ and oxygen radical scavengers can block DNA nuclear fragmentation and the formation of apoptotic bodies after UVA irradiation. ${ }^{28} 33$

\section{"Ultraviolet irradiation generally induces cell death and a drastic increase in the apoptotic activity in irradiated Wistar melanoma cell lines, suggesting excessive under- lying DNA damage beyond the capacity of the repair system"}

In vivo, melanoma cells are traditionally thought to be highly radioresistant. However, several factors may have contributed to the response of the melanoma cells to UVR seen in our study. First, the radioresistance of melanoma cells was noted in an in vivo system, where skin microenvironmental factors probably influence the cells and contribute to 
Table 1 Microsatellite instability in Wistar melanoma (WM) cell lines

\begin{tabular}{|c|c|c|c|c|c|c|c|}
\hline \multirow[b]{2}{*}{ Chromosome } & \multirow[b]{2}{*}{ Marker } & \multicolumn{3}{|l|}{ UVB } & \multicolumn{3}{|l|}{ UVA } \\
\hline & & WM35 & WM1650 & WM3211 & WM35 & WM1650 & WM3211 \\
\hline $1 p 36.33$ & D1S243 & NA & NA & MSS & MSS & MSS & MSS \\
\hline $1 p 36.33$ & D1S468 & MSS & MSS & NA & MSS & MSS & MSS \\
\hline $1 \mathrm{p} 36.32$ & D1S214 & NA & NA & NA & NA & NA & NA \\
\hline $1 p 36.32$ & DIS2663 & MSS & MSS & MSI & MSS & MSS & MSS \\
\hline $1 p 36.32$ & D1S2642 & MSS & NA & MSS & MSS & MSS & MSS \\
\hline $1 p 36.23$ & D1S489 & MSS & MSS & MSS & NA & NA & NA \\
\hline $1 p 36.23$ & D1S228 & MSS & MSS & MSS & MSS & NA & MSS \\
\hline $1 \mathrm{p} 35$ & D1S2734 & MSI & MSS & MSS & MSS & MSS & MSS \\
\hline $1 p 34$ & DIS513 & MSS & MSS & MSI & NA & NA & NA \\
\hline 1 p34 & D1S233 & MSI & MSS & MSI & MSI & NA & MSS \\
\hline $1 p 34$ & D1S2832 & MSS & MSS & MSS & NA & NA & MSS \\
\hline $1 p 33$ & MYCL1 & MSI & MSS & MSS & MSS & NA & MSS \\
\hline $2 p$ & BAT-26 & MSS & MSS & MSS & NA & NA & NA \\
\hline $3 p$ & BAT40 & MSS & MSS & MSS & NA & NA & NA \\
\hline $4 q 12$ & BAT-25 & MSS & MSS & MSS & MSS & NA & MSS \\
\hline $17 p$ & TP53 & MSS & MSS & MSI & MSS & NA & MSS \\
\hline $9 p 22$ & D9S162 & NA & NA & MSS & NA & NA & NA \\
\hline $9 p 22$ & IFNA & MSI & MSS & MSS & NA & NA & MSS \\
\hline $9 p 21$ & D9S171 & NA & NA & MSI & NA & NA & NA \\
\hline $9 p 21$ & D9S126 & NA & NA & NA & NA & NA & NA \\
\hline $9 p 21$ & D9S169 & NA & NA & NA & NA & NA & NA \\
\hline
\end{tabular}

this resistance. The in vitro system used here is not affected by changes in the skin microenvironment after UV exposure. Second, ionising rather than non-ionising irradiation (UVR) has been used in the radiotherapy of melanoma.

The MSI-L pattern found in irradiated WM cell lines is in keeping with other studies reporting similar changes in excised melanocytic lesions. ${ }^{8}{ }^{22}$ This finding also supports our hypothesis that UVR can induce MSI in these lesions, suggests that MSI can arise early in melanoma pathogenesis, and suggests that UVR may be a driving force in the evolution of at least some CMMs, such as those arising on sun exposed skin. Because MSI may affect the function of the genes in which the microsatellites reside, the presence of MSI in the markers flanking the melanoma susceptibility genes in the $1 p$ and $9 p$ regions warrants further mutational analysis of these genes. Interestingly, UVB produced more MSI than UVA. In this regard, because UVB penetrates less deeply than UVA, the greater effect of UVB on MSI may help explain why most CMMs begin superficially in or near the epidermis.

We suggest three possibilities to support our hypothesis and to explain how UVR was able to induce MSI in the irradiated WM cell lines. First, the presence of MSI after a single exposure to UVR may merely represent a hypermutability state in these cell lines. In this regard, because exposure to UVR in vitro represents a dramatic change in the environment of WM tumour cells, it is conceivable that the cells acquire selective advantages by generating additional mutations, perhaps in the microsatellite repeats, to adjust to the in vitro conditions. ${ }^{34}$

Second, the presence of MSI after UV exposure may reflect underlying DNA damage by reactive oxygen species. Because UVR inhibits free radical scavenging activity ${ }^{35}$ and inactivates antioxidant enzymes, ${ }^{56}$ it enhances DNA damage by reactive oxygen radicals. The generation of these radicals is estimated to be responsible for 20000 hits to $\mathrm{DNA} / \mathrm{cell} / \mathrm{day},{ }^{37-40}$ representing a major source of mutations. The role of oxidative stress in melanoma tumorigenesis is supported by three observations, namely: (1) oxygen radical induced DNA damage is involved in some tumours, such as breast cancers $^{41}$; (2) CMM cell lines constitutively produce and accumulate hydrogen peroxide at levels comparable to activated polymorphonuclear lymphocytes ${ }^{42}$; and (3) exposure of DNA to reactive oxygen species in vitro can induce MSI, ${ }^{43}$ even in the absence of MMR gene defects, by several mechanisms. One of these mechanisms involves the retardation of DNA polymerase at sites of oxidative base damage, with subsequent strand displacement and misalignment of the growing strands at different positions on the template. Furthermore, strand scission within the microsatellite repeat sequences by reactive oxygen species enhances the possibility of strand misalignment, with the subsequent generation of insertion or deletion loops. The reactive oxygen radicals can also induce single strand breaks in the microsatellite sequences, increasing the formation of slipped strand intermediates. ${ }^{44}$

The third possibility is that the presence of MSI after UV exposure may reflect underlying DNA replication infidelity. As a part of the response to the UV irradiation of WM cell lines, there is accumulation of damaged DNA photoproducts that stimulate the induction of stress induced secreted proteins in the cell lines. ${ }^{45}$ Subsequently, these proteins promote activation of the genes encoding extracellular proteins,${ }^{46}$ cytokines, ${ }^{47}$ and several yet unidentified proteins. These three protein classes are also involved in inducing replication infidelity, and may favour genetic instability and oncogenic transformation. ${ }^{48}$ In support of this concept, the secretion of these proteins was found to induce genetic instability in mouse T lymphoma cell lines after $\mathrm{UVR}^{4}{ }^{4}$ and

\section{Take home messages}

- Ultraviolet (UV) irradiation induced pronounced apoptosis in radial growth phase melanoma cells, with UVA having a greater effect than UVB

- UV also induced microsatellite instability (MSI) and was more prevalent after UVB than UVA irradiation

- Thus, the ability of erythemogenic UV irradiation to induce both apoptosis and MSI in radial growth phase melanoma cells suggests that it plays a role in the pathogenesis of melanoma

- This instability may reflect a hypermutability state, oxidative stress induced DNA damage, replication infidelity, or a combination of these factors 
some of these proteins are constitutively expressed in several cancer prone syndromes ${ }^{49}$ and tumour cell lines. ${ }^{50}$

The absence of LOH after UV irradiation in WM cells is in agreement with previous studies, ${ }^{51}$ and suggests that the initial genetic events after UVR do not include LOH at an early stage. This observation is in accordance with the fact that $\mathrm{LOH}$ is usually associated with exposure to ionising irradiation but not to non-ionising irradiation. ${ }^{52}$

Of note, further experiments on the same cell lines are suggestive of increased malignant potential. In this regard, UVR was able to induce both point mutations in the mismatch repair genes ${ }^{53}{ }^{54}$ and ultrastructural changes in keeping with malignant changes. However, determining whether the cells that survive UVR have in fact an increased tumorigenic potential relative to the parental ones (for example, growth as xenografts in immunosuppressed mice) will require additional experiments. The results of our present study will be useful to compare and contrast with such subsequent investigations.

To the best of our knowledge, our study is the first to suggest the induction of apoptosis and MSI in WM cell lines after exposure to UVR. However, whether MSI reflects a hypermutability state, oxidative stress induced DNA damage, replication infidelity, or a combination of these three must be determined by further investigations.

\section{ACKNOWLEDGEMENTS}

This work was supported by Merit Review Funding from the Department of Veteran Affairs and NIH grant AR01326. The authors thank Dr S Emancipator for his exceptional guidance and helpful insight throughout this project. We are also grateful to Ms K Kleckner for preparing the tables and figures for submission.

\section{Authors' affiliations}

M R Hussein*, Department of Pathology, Faculty of Medicine, Assuit University, Assuit, Egypt

A K Haemelt, Brown Medical School, Providence, RI 02912, USA O Sudilovsky, Institute of Pathology, Case Western Reserve University and University Hospitals of Cleveland, Cleveland, OH 44106, USA

G S Wood, Department of Dermatology, University of Wisconsin and William S Middleton Memorial Veteran Hospital, Madison, WI 53705, USA

*Former address: Institute of Pathology, Case Western Reserve University and University Hospitals of Cleveland, Cleveland, $\mathrm{OH}$ 44106, USA †Former address: Department of Dermatology, University of Wisconsin and William S Middleton Memorial Veteran Hospital, Madison, WI 53705, USA

\section{REFERENCES}

1 Abarca JF, Casiccia CC. Skin cancer and ultraviolet-B radiation under the Antarctic ozone hole: southern Chile, 1987-2000. Photodermatol Photoimmunol Photomed 2002;18:294-302.

2 Freeman SE, Hacham H, Gange RW, et al. Wavelength dependence of pyrimidine dimer formation in DNA of human skin irradiated in situ with ultraviolet light. Proc Natl Acad Sci U S A 1989;86:5605-9.

3 Mitchell DL, Zdzienicka MZ, van Zeeland AA, et al. Intermediate (6-4) photoproduct repair in Chinese hamster V79 mutant V-HI correlates with intermediate levels of DNA incision and repair replication. Mutat Res 1989;226:43-7.

4 Boesen JJ, Dieteren N, Bal E, et al. A possible factor in genetic instability of cancer cells: stress-induced secreted proteins lead to decrease in replication fidelity. Carcinogenesis 1992;13:2407-13.

5 Fuchs J, Packer L. Ultraviolet irradiation and the skin antioxidant system [published erratum appears in Photodermatol Photoimmunol Photomed 1990;7:183]. Photodermatol Photoimmunol Photomed 1990;7:90-2.

6 Peak MJ, Peak JG, Carnes BA. Induction of direct and indirect single-strand breaks in human cell DNA by far- and near-ultraviolet radiations: action spectrum and mechanisms. Photochem Photobiol 1987;45:381-7.

7 Kochevar IE, Moran M, Lyon N, et al. Effects of systemic indomethacin, meclizine, and BW755C on chronic ultraviolet B-induced effects in hairless mouse skin. J Invest Dermatol 1993;100:186-93.

8 Hussein MR, Sun M, Tuthill RJ, et al. Comprehensive analysis of 112 melanocytic skin lesions demonstrates microsatellite instability in melanomas and dysplastic nevi, but not in benign nevi. J Cutan Pathol $2001 ; 28: 343-50$.

9 Palmieri G, Cossu A, Ascierto PA, et al. Definition of the role of chromosome 9p21 in sporadic melanoma through genetic analysis of primary tumours and their metastases. The melanoma cooperative group. $\mathrm{Br} J$ Cancer 2000;83:1707-14.

10 Redman JC. Stratospheric ozone depletion. A proposed solution to the problem. Am J Dermatopathol 1987;9:457-8.

11 Elder DE. Human melanocytic neoplasms and their etiologic relationship with sunlight. J Invest Dermatol 1989;92:297S-303S.

12 Donawho CK, Kripke ML. Photoimmunology of experimental melanoma. Cancer Metastasis Rev 1991;10:177-88.

13 Hussein MR, Haemel AK, Wood GS. Apoptosis and melanoma: molecular mechanisms. J Pathol 2003;199:275-88.

14 Herzinger T, Funk JO, Hillmer K, et al. Ultraviolet B irradiation-induced G2 cell cycle arrest in human keratinocytes by inhibitory phosphorylation of the cdc2 cell cycle kinase. Oncogene 1995;11:2151-6.

15 Kripke ML. Latency, histology, and antigenicity of tumors induced by ultraviolet light in three inbred mouse strains. Cancer Res 1977;37:1395-400.

16 Bruls WA, Slaper H, van der Leun JC, et al. Transmission of human epidermis and stratum corneum as a function of thickness in the ultraviolet and visible wavelengths. Photochem Photobiol 1984;40:485-94.

17 Bruls WA, van der Leun JC. Forward scattering properties of human epidermal layers. Photochem Photobiol 1984;40:231-42.

18 Bruls WA, van Weelden H, van der Leun JC. Transmission of UV-radiation through human epidermal layers as a factor influencing the minimal erythema dose. Photochem Photobiol 1984;39:63-7.

19 Del Bino G, Lassota P, Darzynkiewicz Z. The S-phase cytotoxicity of camptothecin. Exp Cell Res 1991;193:27-35.

20 Bedaiwy MA, Jeremias E, Gurunluoglu R, et al. Restoration of ovarian function after autotransplantation of intact frozen-thawed sheep ovaries with microvascular anastomosis. Fertil Steril 2003;79:594-602.

21 Cottu PH, Muzeau F, Estreicher A, et al. Inverse correlation between RER+ status and p53 mutation in colorectal cancer cell lines. Oncogene 1996;13:2727-30

22 Hussein MR, Sun M, Roggero E, et al. Loss of heterozygosity, microsatellite instability, and mismatch repair protein alterations in the radial growth phase of cutaneous malignant melanomas. Mol Carcinog 2002;34:35-44.

23 Donawho CK, Kripke ML. Evidence that the local effect of ultraviolet radiation on the growth of murine melanomas is immunologically mediated. Cancer Res 1991;51:4176-81.

24 Hahne M, Rimoldi D, Schroter M, et al. Melanoma cell expression of Fas (Apo-1/CD95) ligand: implications for tumor immune escape. Science 1996;274:1363-6

25 Friedmann PS, Gilchrest BA. Ultraviolet radiation directly induces pigment production by cultured human melanocytes. J Cell Physiol 1987; 133:88-94.

26 Abdel-Malek Z, Swope V, Smalara D, et al. Analysis of the UV-induced melanogenesis and growth arrest of human melanocytes. Pigment Cell Res 1994;7:326-32.

27 Musk P, Parsons PG. Resistance of pigmented human cells to killing by sunlight and oxygen radicals. Photochem Photobiol 1987;46:489-94.

28 Wang Y, Rosenstein B, Goldwyn S, et al. Differential regulation of P53 and $\mathrm{Bcl}-2$ expression by ultraviolet A and B. J Invest Dermatol 1998;1 11:380-4.

29 Ouhtit A, Muller HK, Davis DW, et al. Temporal events in skin injury and the early adaptive responses in ultraviolet-irradiated mouse skin. Am J Pathol 2000;156:201-7.

30 Godar DE, Lucas AD. Spectral dependence of UV-induced immediate and delayed apoptosis: the role of membrane and DNA damage. Photochem Photobiol 1995;62:108-13.

31 Buttke TM, Sandstrom PA. Oxidative stress as a mediator of apoptosis. Immunol Today 1994;15:7-10.

32 Lennon SV, Martin SJ, Cotter TG. Dose-dependent induction of apoptosis in human tumour cell lines by widely diverging stimuli. Cell Prolif 1991;24:203-14.

33 Verhaegen S, McGowan AJ, Brophy AR, et al. Inhibition of apoptosis by antioxidants in the human HL-60 leukemia cell line. Biochem Pharmacol 1995;50:1021-9

34 Molenaar JJ, Gerard B, Chambon-Pautas C, et al. Microsatellite instability and frameshift mutations in BAX and transforming growth factor-beta RII genes are very uncommon in acute lymphoblastic leukemia in vivo but not in cell lines. Blood 1998;92:230-3.

35 Fuchs J, Huflej† ME, Rothfuss LM, et al. Impairment of enzymic and nonenzymic antioxidants in skin by UVB irradiation. J Invest Dermatol 1989;93:769-73

36 Whiteside C, Hassan HM. Role of oxyradicals in the inactivation of catalase by ozone. Free Radic Biol Med 1988;5:305-12.

37 Cerutti PA. Prooxidant states and tumor promotion. Science 1985;227:375-81.

38 Feig DI, Reid TM, Loeb LA. Reactive oxygen species in tumorigenesis. Cancer Res 1994;54:1890s-4s.

39 Ames BN, Shigenaga MK, Hagen TM. Oxidants, antioxidants, and the degenerative diseases of aging. Proc Natl Acad Sci U S A 1993;90:7915-22.

40 Beckman KB, Ames BN. Oxidative decay of DNA. J Biol Chem 1997;272:19633-6.

41 Malins DC, Polissar NL, Gunselman SJ. Progression of human breast cancers to the metastatic state is linked to hydroxyl radical-induced DNA damage. Proc Natl Acad Sci U S A 1996;93:2557-63.

42 Szatrowski TP, Nathan CF. Production of large amounts of hydrogen peroxide by human tumor cells. Cancer Res 1991;51:794-8.

43 Jackson AL, Chen R, Loeb LA. Induction of microsatellite instability by oxidative DNA damage. Proc Natl Acad Sci U S A 1998;95:12468-73.

44 Jackson AL, Loeb LA. The mutation rate and cancer. Genetics 1998; 148: 1483-90. 
45 Stein B, Rahmsdorf HJ, Steffen A, et al. UV-induced DNA damage is an intermediate step in UV-induced expression of human immunodeficiency virus type 1, collagenase, c-fos, and metallothionein. Mol Cell Biol 1989:9:5169-81.

46 Angel P, Poting A, Mallick $U$, et al. Induction of metallothionein and other mRNA species by carcinogens and tumor promoters in primary human skin fibroblasts. Mol Cell Biol 1986;6:1760-6.

47 Kirnbauer R, Kock A, Neuner P, et al. Regulation of epidermal cell interleukin6 production by UV light and corticosteroids. J Invest Dermatol 1991:96:484-9.

48 Schorpp M, Mallick U, Rahmsdorf HJ, et al. UV-induced extracellular factor from human fibroblasts communicates the UV response to nonirradiated cells. Cell 1984;37:861-8.

49 Mallick U, Rahmsdorf HJ, Yamamoto N, et al. 12-O-Tetradecanoylphorbol 13-acetate-inducible proteins are synthesized at an increased rate in Bloom syndrome fibroblasts. Proc Natl Acad Sci U S A 1982;79:7886-90.
50 Matsuguchi T, Okamura S, Kawasaki $\mathrm{C}$, et al Constitutive production of granulocyte colony-stimulating factor and interleukin- 6 by a human lung cancer cell line, KSNY: gene amplification and increased mRNA stability. Eur J Haematol 1991;47:128-33.

51 Boni R, Matt D, Burg G, et al. Ultraviolet-induced acute histological changes in irradiated nevi are not associated with allelic loss. Arch Dermatol 1998;134:853-6.

52 Thomas JW, LaMantia C, Magnuson T. X-ray-induced mutations in mouse embryonic stem cells. Proc Natl Acad Sci U S A 1998;95:1114-19.

53 Hussein MR, Wood GS. hMLH1 and hMSH2 gene mutations are present in radial growth-phase cutaneous malignant melanoma cell lines and can be induced further by ultraviolet-B irradiation. Exp Dermatol 2003; 12:872-5.

54 Hussein MR, Hassan M, Wood GS. Morphological changes and apoptosis in radial growth phase melanoma cell lines following ultraviolet-B irradiation. Am J Dermatopathol 2003;25:466-72.

\section{Clinical Evidence-Call for contributors}

Clinical Evidence is a regularly updated evidence-based journal available worldwide both as a paper version and on the internet. Clinical Evidence needs to recruit a number of new contributors. Contributors are healthcare professionals or epidemiologists with experience in evidence-based medicine and the ability to write in a concise and structured way.

\section{Areas for which we are currently seeking authors:}

- Child health: nocturnal enuresis

- Eye disorders: bacterial conjunctivitis

- Male health: prostate cancer (metastatic)

- Women's health: pre-menstrual syndrome; pyelonephritis in non-pregnant women

However, we are always looking for others, so do not let this list discourage you.

Being a contributor involves:

- Selecting from a validated, screened search (performed by in-house Information Specialists) epidemiologically sound studies for inclusion.

- Documenting your decisions about which studies to include on an inclusion and exclusion form, which we keep on file.

- Writing the text to a highly structured template (about 1500-3000 words), using evidence from the final studies chosen, within 8-10 weeks of receiving the literature search.

- Working with Clinical Evidence editors to ensure that the final text meets epidemiological and style standards.

- Updating the text every six months using any new, sound evidence that becomes available. The Clinical Evidence in-house team will conduct the searches for contributors; your task is simply to filter out high quality studies and incorporate them in the existing text.

- To expand the topic to include a new question about once every 12-18 months.

If you would like to become a contributor for Clinical Evidence or require more information about what this involves please send your contact details and a copy of your CV, clearly stating the clinical area you are interested in, to Klara Brunnhuber (kbrunnhuber@ bmigroup.com).

\section{Call for peer reviewers}

Clinical Evidence also needs to recruit a number of new peer reviewers specifically with an interest in the clinical areas stated above, and also others related to general practice. Peer reviewers are healthcare professionals or epidemiologists with experience in evidence-based medicine. As a peer reviewer you would be asked for your views on the clinical relevance, validity, and accessibility of specific topics within the journal, and their usefulness to the intended audience (international generalists and healthcare professionals, possibly with limited statistical knowledge). Topics are usually 1500-3000 words in length and we would ask you to review between 2-5 topics per year. The peer review process takes place throughout the year, and our turnaround time for each review is ideally 10-14 days.

If you are interested in becoming a peer reviewer for Clinical Evidence, please complete the peer review questionnaire at www.clinicalevidence.com or contact Klara Brunnhuber (kbrunnhuber@bmigroup.com). 